\title{
RTK KINEMATIC POSITIONING ACCURACY WITH DOUBLE PHASE DIFFERENCE OF SIS GNSS SIGNALS
}

Lucjan Setlak, Rafal Kowalik

Department of Avionics and Control Systems, Faculty of Aviation Division, Military University of Aviation, Deblin, Poland

*E-mail of corresponding author: r.kowalik@law.mil.pl

\section{Resume}

The article presents results of verification of the kinematic measurements usefulness for precise real-time positioning RTK in the local reference system. These measurements allow for continuous RTK measurements in the event of temporary interruptions in radio or internet connections, which are the main reason for interruptions in RTK kinematic measurements and cause a decrease in the reliability and efficiency of this positioning method. Short interruptions communication are allowed during the loss of the key correction stream from the local RTK support network, so the global corrections obtained from the geostationary satellite are used. The aim of the article was to analyze the accuracy of measuring the position of moving objects. Practical conclusions were formulated according to the research subject, the presented mathematical models, the experiment and the analysis of the obtained results.

\section{Article info}

Received 8 October 2020

Accepted 4 November 2020

Online 26 May 2021

\section{Keywords:}

real-time kinematic (RTK)

positioning,

double signal difference,

GNSS system

\section{Introduction}

The key point of precise positioning of the Global Navigation Satellite Syste) (GNSS) is the ability to mitigate (reduce) all the potential source errors and interference in the system. All errors in the GNSS observations caused by signal propagation, the environment around the receiver and the equipment of the recipient, must be mitigated [1-4].

Limitation can be improved by modeling, estimating and creating individual combinations of station observations, as well as application of the differential mechanism of technique. Such errors of the analyzed observation are the subject of detailed considerations, included in the further part of this article.

\section{Observations of the GNSS navigation system}

The basic measurements recorded by the GNSS receiver are the differences in time or phase between the signals transmitted by the GNSS satellites and the reference signals generated inside the receiver. Signals of the GNSS system are transmitted at different frequencies, while the GNSS system receivers produce observable signals different from the signals of the navigation system [5-7]. Types of observation of the pseudorange code, carrier phase and Doppler phenomenon are discussed in the subsequent parts of individual subsections.

\subsection{Model for determining the pseudorange}

Unlike the terrestrial electronic distance measurements, the GNSS system uses an „one-way concept" in which satellite and receiver clocks are involved. Therefore, the ranges are affected by the satellite clock and receiver errors. Therefore, they are marked as pseudoranges. The GPS (Global Positioning System) receiver generates a copy of the pseudo-random code and compares it to that coming from the satellite [8-9].

The time offset is calculated by the autocorrelation function between the received pseudo-random code from the satellite and generated by the receiver. This type of shift includes the signal travel time and incorrect synchronization of satellite clocks and receivers. Pseudorange measurements usually have an accuracy of 1-10 meters.

The following is the equation for the observed pseudoranges [10-12]:

$$
\begin{aligned}
& P_{r, j}^{s}=\rho_{r}^{s}+c\left(d t_{r}-d t^{s}\right)+I_{r, j}^{s}+ \\
& +T_{r}^{s}+b_{r, j}-b_{j}^{s}+\varepsilon_{r, j}^{s},
\end{aligned}
$$

where: superscript $s$ - refers to a given satellite, subscript $r$ - refers to the receiver, subscript 
$j$ - identifies the frequency, $P_{r, j}^{s}$ - is the pseudorange between the receiver $r$ and the satellite $j, \rho_{r}^{s}-$ is the geometric distance from the receiver $r$ to the satellite $s$, including relativistic corrections, as well as the phase shift and variations, $c$ - means the speed of light in vacuum.

In addition, $d t_{r}$ and $d t^{s}$ - these are receiver and satellite clock offsets relative to system time, $I_{r, j}^{s}$ - is the ionospheric delay in the signal path of the frequency $j, T_{r}^{s}$ - is the tropospheric delay in the signal path, and $b_{r, j}$ and $b_{j}^{s}$ - are the deviation of the receiver code $r$ and the satellite $s$ on the frequency $j$, respectively $\varepsilon_{r, j}^{s}$ - represents the effect of observational noise and all the non-modeled error sources, such as: satellite clock errors, predicted orbits and inaccuracies in ionospheric and tropospheric modeling, with the meter [m] being used for all the conditions.

In this work, pseudorange measurement is mainly used to obtain approximate or initial positions and construct ionosphere and geometry-free measurements.

\subsection{Phases of SIS carrier signals}

Observations of the carrier phase of the SIS signal (Signal in Space) are obtained by comparing phases between the signal transmitted by the satellite and a similar (analogous) signal generated by the receiver. The receiver registers a fraction of the satellite phase of the GNSS system and tracks changes in the received carrier phase, where the initial phase, called ambiguity, is unknown [13-14].

In order to use the phase observations, the so-called phase ambiguity must be resolved (analyzed). In addition, it should be noted that phase observations have noises of a few millimeters and are much more accurate than pseudoranges.

The carrier phase measurement equation can be written as [15-17]:

$\lambda_{j}^{s} * \varphi_{r, j}^{s}=\rho_{r}^{s}+c *\left(d t_{r}-d t^{s}\right)-I_{r, j}^{s}+T_{r}^{s}+\lambda_{j}^{s} *$

$* N_{r, j}^{s}+d_{r, j}-d_{j}^{s}+e_{r, j}^{s}$,

where: $\lambda_{j}^{s}$ - is the satellite carrier wavelength $s$ on the frequency $j, \varphi_{r, j}^{s}$ - is the carrier phase of the observation in cycles between the receiver $r$ and the satellite $s$ on the frequency $j$ and $\rho_{r}^{s}$ - means pseudoranges the geometric distance from satellite $s$ to receiver $r$, containing not only relativistic corrections, but the phase shift and variations, as well, with $I_{r, j}^{s}$ - being the ionospheric advance of the carrier phase on a signal path on the frequency $j$ scaled to a unit of length, having the same magnitude as for pseudorange measurements, but the opposite sign.
In addition, $N_{r, j}^{s}$ - is an integer ambiguity for a specific receiver-satellite pair with a frequency $j, d_{r, j}$ and $d_{j}^{s}$ - are the deviation of the carrier phase of the receiver $r$ and the satellite $s$ on the frequency $j$ and $e_{r, j}^{s}$ - represent the unmodified effects, modeling errors and measurement errors for the observation of the carrier phase, which are three or four orders of magnitude smaller than for the code measurements.

\subsection{Doppler effect in SIS signals}

The Doppler effect is a phenomenon of the frequency shift of the induced electromagnetic signal by the relative movement of the emitter in relation to the receiver.

In the first approximation, the Doppler change is given as [18-20]:

$D_{r, j}^{s}=f_{j}^{s}-f_{r, j}^{s}=\frac{V_{\rho_{r}^{s}}^{s}}{c} f_{j}^{s}=\frac{V_{\rho_{r}^{s}}^{s}}{\lambda_{j}^{s}}$,

where: $D_{r, j}^{s}$ - is the Doppler shift between the receiver $r$ and the satellite $s$ on the frequency $j, f_{j}^{s}$ - means the frequency emitted $j$ to the satellite $s, f_{r, j}^{s}$ - means the frequency $j$ received from the satellite $s, V_{\rho_{r}^{s}}-$ is the relative speed along the distance line between the satellite $s$ and the receiver $r$, and $\lambda_{j}^{s}$ - is the carrier wavelength of the satellite $s$ on the frequency $j$.

Equation (3) for the observed Doppler shift scaled to range speed is given as:

$$
V_{\rho_{r}^{s}}=\lambda_{j}^{s} * D_{r, j}^{s}=\dot{\rho}_{r}^{s}+c *\left(d t_{r}-d t^{s}\right)+\varepsilon,
$$

where: derivatives in relation to time are marked with a dot and $\varepsilon$ - is a measurement error.

It should be noted that the Doppler shift is a by-product of both carrier phase measurements, independently observable and a measure of instantaneous range speed.

For example, when the satellite is moving towards the GNSS receiver, the Doppler shift is positive, so more Doppler counts are obtained when the range decreases.

\section{Linear combinations of GNSS system observation}

Several linear combinations of the GNSS primary carrier phase and code measurements are used in data analysis to eliminate or reduce some of the observation equation components. For example, a linear combination to remove the ionosphere effect can be created [21-22].

These types of combinations are listed and discussed later in this article. Parameter $\varphi_{j}$ represents phase observations in cycles with a frequency $j$, while $P_{j}$ represents code observations in meters on a frequency $j$. 


\subsection{Linear combinations without influence of the ionosphere}

The ionospheric delay, caused by the collapse of the GNSS electromagnetic signal, where propagation through the ionospheric layer in the atmosphere, is in the range of $6-150[\mathrm{~m}]$. A normal approach to eliminate ionospheric delay is created by a dedicated LC (Linear Combination) of GNSS observation. This kind of combination is called "ionosphere-free LC measurement".

For observation of the carrier phase of Equation (2) and observation of the Equation code (1), the combination without the influence of the ionosphere can be written as [23-25]:

$$
\varphi_{L C}=\frac{f_{1}^{2}}{f_{1}^{2}-f_{2}^{2}} \varphi_{1}-\frac{f_{1} * f_{2}}{f_{1}^{2}-f_{2}^{2}} \varphi_{2}
$$

and:

$$
P_{L C}=\frac{f_{1}^{2}}{f_{1}^{2}-f_{2}^{2}} P_{1}-\frac{f_{2}^{2}}{f_{1}^{2}-f_{2}^{2}} P_{2} .
$$

The ionospheric advance depends on frequency. The above Equations (5) and (6) eliminate the first-order ionospheric advance effect of the observation, which is widely used in the GNSS data processing [26-28]. The disadvantage of this linear combination is that noise from $\varphi_{1}$ and $\varphi_{2}$ measurements increases threefold and that ambiguities cannot be directly resolved as integers.

In the case of receivers that have two-phase capabilities, the LC combination is usually the preferred method in geodetic and atmospheric applications for estimating coordinates, tropospheric deceleration values and receiver clock deviation.

\section{2 "Wide-Lane" linear combination}

The „Wide-Lane" (WL) observation is a popular linear combination mainly used for ambiguity and can be described as:

$\varphi_{W L}=\varphi_{1}-\varphi_{2}$

The combination of the wavelength $\lambda_{W L}$ measurements of the carrier phases $L 1$ and $L 2$ is 86 [cm]. This long wavelength simplifies the solution to the ambiguity. It is widely used in analysis of the GNSS stations more than several dozen kilometers apart. In the data pre-processing process, this type of solution can also be used to detect signal cycles.

\subsection{Linear combination for determining the position of the moving objects}

It should be noted that since the parameters $\varphi_{1}$ and $\varphi_{2}$ carry the same geometrical information, the number of independent positions can be constructed by subtracting $\varphi_{2}$, the carrier phase observation multiplied by the frequency ratio, from $\varphi_{1}$, which can be recorded as:

$\varphi_{E X W L}=\varphi_{1}-\frac{f_{1}}{f_{2}} \varphi_{2}$.

This type of linear combination eliminates geometry (orbits, position coordinates), troposphere and clock synchronization elements in equation with the carrier phase. In this way, it is often called a linear combination not related to geometry or extra-wide-lane (EWL/ EX_WL). Because the combination of initial phase ambiguities remains, EX_WL can only represent a set of ionospheric delay variations during continuous tracking [29-30].

For the initial processing of GPS data, it is possible to construct a polynomial fit for EX_WL and to identify discontinuities such as cycle sections or outliers. However, in conditions of the high ionosphere activity, it is difficult to detect cycles slip with a linear ionospheric combination.

\section{4 „MW Wide-Lane” linear combination}

Observation of wide-lane MW (Melbourne-Wübbena combination) in Equation (7) still contains information about the position, with ionospheric effects and position information from wide-lane observations can be can be eliminated (removed), except that the ionosphere effects on the code and phase measurement are equal, but have opposite signs in Equation (1) and (2).

In the case where both code and phase information are available on two frequencies, observation without position and ionosphere is given in the form [31-32]:

$\varphi_{M W W L}=\varphi_{1}-\varphi_{2}-\frac{f_{1}-f_{2}}{f_{1}+f_{2}}\left(\frac{P_{1}}{\lambda_{1}}+\frac{P_{2}}{\lambda_{2}}\right)$.

This state, called the Melbourne-Wübbena combination, combines phase and code observations to eliminate ionospheric, geometric and clock effects and will be used to initiate ambiguities in the processing of the GNSS navigation system data. In addition, it should be noted that only multipath error and pseudorange noise are still included in the MW_WL observation, but can be reduced or eliminated by averaging many epochs.

\section{Kinematic positioning based on multiple reference stations}

This section primarily deals with the GNSS DD (double-difference) positioning approach based on multiple reference stations that are used to determine the baseline vectors between simultaneous observing receivers. Issues of this section focus on discussion of the GNSS DD positioning, with particular emphasis 


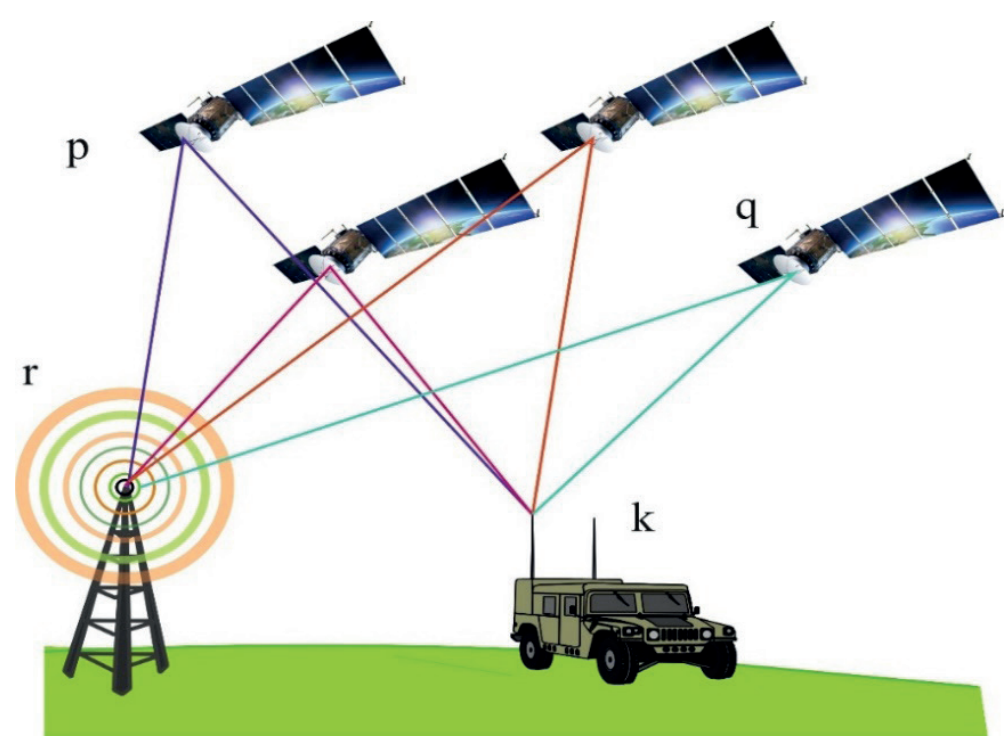

Figure 1 Illustration for positioning the GNSS DD system

on the analysis of observation equations for a single difference SD (single-difference) and DD. The challenge of DD positioning in a wide region was presented using the ultra-short and ultra-long base experiments. In addition, the kinematic positioning approach of many reference stations, based on apriori constraints, relates to the precise kinematic positioning of the GNSS system in a wide area.

At the final stage of consideration, solid Kalman filter theory is used to suppress the effect of outliers observations on trajectory estimates for air gravimetry.

\subsection{Double-Difference positioning}

The DD positioning is a classic GNSS system data processing method. This method is regularly used to eliminate or reduce errors between the satellite and the receiver. In addition, since observations of the carrier phase on satellites of the GNSS system can be used to determine the user's position even more precisely than by means of pseudorange measurements, in this part of this subsection the principle of $\mathrm{DD}$ carrier phase positioning is presented [33-35].

\subsection{The principle of positioning the classic double difference}

A simple example of positioning the DD (double difference) is shown in Figure 1, whereby $p$ and $q$ - mean the GNSS satellites, $r$ - means the reference station and $k$ - means the kinematic station.

According to observation of the carrier phase of Equation (2), the observations of the carrier phase of the reference of the station $r$ and the kinematic station $k$ to a common satellite $p$ can be written as:

$\lambda_{j}^{p} * \varphi_{r, j}^{p}=\rho_{r}^{p}+c *\left(d t_{r}-d t^{p}\right)-I_{r, j}^{p}+T_{r}^{p}+\lambda_{j}^{p} *$

$* N_{r, j}^{p}+d_{r, j}-d_{j}^{p}+e_{r, j}^{p}$, $\lambda_{j}^{p} * \varphi_{k, j}^{p}=\rho_{k}^{p}+c *\left(d t_{k}-d t^{p}\right)-I_{k, j}^{p}+T_{k}^{p}+\lambda_{j}^{p} *$

$* N_{k, j}^{p}+d_{k, j}-d_{j}^{p}+e_{k, j}^{p}$,

By creating a single difference, subtracting the measurement at the reference station from that at the kinematic station, the satellite clock $d t^{p}$ and the satellite phase deviation $d_{j}^{p}$ (which are common errors for both observers) are canceled by the following equation written in the form:

$$
\begin{aligned}
& \lambda_{j}^{p} * \Delta \varphi_{k-j, r}^{p}=\Delta \rho_{k-r}^{p}+c * \Delta d t_{k-r}-\Delta T_{k-r}^{p}+ \\
& +\lambda_{j}^{p} * N_{k-r j}^{p}+\Delta d t_{k-r, j}+\Delta e_{k-r, j}^{p},
\end{aligned}
$$

where: operator $\Delta$ - indicates for example a single difference $\varphi_{k-j, r}^{p}$ marked as $\varphi_{k, j}^{p}-\varphi_{k, j}^{p}$.

It should be noted that if both antennas are close together, for example less than $10[\mathrm{~km}]$ on the ground, the tropospheric delays are approximately the same, so that the differences in tropospheric delays $\Delta T_{k-r}^{p}$ are small and significantly reduced in Equation (12).

However, for medium and long baselines, the path of the signal traveling through the troposphere is different for each station, especially if the receivers are at different altitudes. This may be the case e.g. in mountainous regions or when an airplane approaches an airport. Thus, the tropospheric path delay is not canceled in positioning a single difference for medium and long baselines. Assuming that the kinematic station is close enough to the reference station, the path of the GNSS satellite signal through the ionosphere will be almost identical for the reference station and the kinematic station. Hence, the ionospheric delay can be significantly reduced and this summation can be made for distances up to about 1000 [km]. For long baselines, ionospheric delay can be eliminated for the first order approximation by creating a ionosphere-free dual frequency observation linear combination. In this 
Table 1 List of equipment selected from the IGS website

\begin{tabular}{clc}
\hline station name & receiver type & antenna type \\
\hline station 1 & JPS LEGACY & LEIAR25.R4 \\
station 2 & JPS LEGACY & LEIAR25.R4 \\
\hline
\end{tabular}

way, the differential ionospheric delay $\Delta I_{k-r j}^{p}$ can be neglected.

Therefore, in this case Equation (12) can be further simplified by writing it as [36-38]:

$\lambda_{j}^{p} * \varphi_{k-j, r}^{p}=\Delta \rho_{k-r}^{p}+c * \Delta d t_{k-r}+\Delta T_{k-r}^{p}+\lambda_{j}^{p} *$

$* \Delta N_{k-r, j}^{p}+\Delta d_{k, j}-d_{k-r j}+e_{k-r, j}^{p}$.

This type of differential processing is called "single difference positioning", namely the differential measurement of two receivers relative to a common satellite. The positioning of a single difference is applied to the satellite $q$ with the signal frequency $i$, which is given as:

$\lambda_{i}^{p} * \varphi_{k-i, r}^{p}=\Delta \rho_{k-r}^{p}+c * \Delta d t_{k-r}+\Delta T_{k-r}^{p}+\lambda_{i}^{p} *$

$* \Delta N_{k-r, i}^{p}+\Delta d_{k, i}-d_{k-r i}+e_{k-r, i}^{p}$.

Assuming the same frequencies $j=i\left(\lambda_{j}^{p}=\lambda_{i}^{q}\right)$ for satellite signals and using denotation $\nabla \Delta_{k-r}^{p-q}=\Delta_{k-r}^{p}-\Delta_{k-r}^{p}$, differentiating the two individual differential observations from Equation (13) and Equation (14), in the same places $r$ and $k$, to two different GNSS system satellites $p$ and $q$, give DD observation as:

$\lambda_{i}^{p} * \nabla \Delta \varphi_{k-r, j}^{p-q}=\nabla \Delta \rho_{k-r}^{p-q}+\nabla \Delta T_{k-r}^{p-q}+\lambda_{j}^{p} *$ $* \nabla \Delta N_{k-r, j}^{p}+\nabla \Delta e_{k-r, j}^{p}$.

The receiver clock error $\Delta d t_{k-r}$ and carrier phase deviation $\Delta d t_{k-r, j}$ are typical errors in Equation (14) and Equation (15), so they can be reduced by positioning DD. Therefore, this is the main reason why the DD positioning is preferably used. However, if the frequencies of signals between the satellites of the GNSS system are different $\left(\lambda_{j}^{p} \neq \lambda_{i}^{q}\right)$, as in the case of the Russian GLONASS system (Global Navigation Satellite System), the carrier phase polarization $\Delta d t_{k-r, j}$ and $\Delta d t_{k-r, i}$ cannot be canceled from Equation (15). Introducing the abbreviated notation, symbolically $\nabla \Delta_{k-r}^{p-q}=\Delta{ }_{k-r}^{p}-\Delta_{k-r}^{q}$, the DD equation for the two different frequency satellites can be given as:

$\lambda_{i}^{p} * \nabla \Delta \varphi_{k-r, j}^{p-q}=\nabla \Delta \rho_{k-r}^{p-q}+\nabla \Delta T_{k-r}^{p-q}+\lambda_{j}^{p} *$ $* \nabla \Delta N \underset{k-r, j}{p-q}+\nabla \Delta e_{k-r, j}^{p-q}$.

Based on the above, it should be noted that it is difficult to separate the carrier phase polarization $\Delta d_{k-r, j} i$ from the ambiguity parameter, so a "float” solution is used to determine the GLONASS system disturbances [39-40]. The procedure described above is called the „DD positioning”, where the satellite orbit error, satellite clock error and receiver clock error have been reduced. For the short baselines, the remaining ionospheric and tropospheric delays can be neglected. For medium and long baselines, the combination of no ionosphere (LC) is used to eliminate the first order ionosphere path delays. The remaining tropospheric delay is reduced by estimating wet zenith delay parameters.

\section{Static experiment based on a GPS+GLONASS system receiver}

In order to test the accuracy, reliability of the algorithm and software in the experiment with static data, static observation data of the GNSS system was randomly selected for testing from the IGS (International GNSS Service) from April 1, 2019, used to increase the accuracy of aircraft positioning. The length of this baseline is approximately $190[\mathrm{~km}]$. Types of the receiver and antenna equipment are given in Table 1.

The number of the GPS, GLONASS and GPS + GLONASS system satellites is shown in Figure 2 as the blue, green and red lines, respectively, where station 2 was selected as the reference station [41-42]. In turn, station 1 was processed by the GNSS LAB using kinematic processing. Results were compared to the coordinates taken from the IGS website (http://www.igs. org) and in the final stage four diagrams were compared (diagram $1 \div 4$ ).

Diagram 1: GPS was used separately to calculate the position of Station 1 .

Diagram 2: The GLONASS system itself was used to calculate the position of Station 1.

Diagram 3: The integrated GPS and GLONASS system was used to calculate the position of Station 1.

Diagram 4: The integrated GPS and GLONASS system was used to calculate the position of Station 1 using VCE Helmert .

Differences between the „real values” and results of diagrams 1-4 are respectively shown in the following figures (Figures 3-6) as time series.

The above experiments, based on the kinematic processing of static data, illustrate the effectiveness, repeatability and stability of the proposed method in static data. Accuracy of the kinematic positioning of the GNSS system, based on the (single) GLONASS system itself, is slightly lower than the accuracy of only the GPS system. Combination of GPS and GLONASS is better 


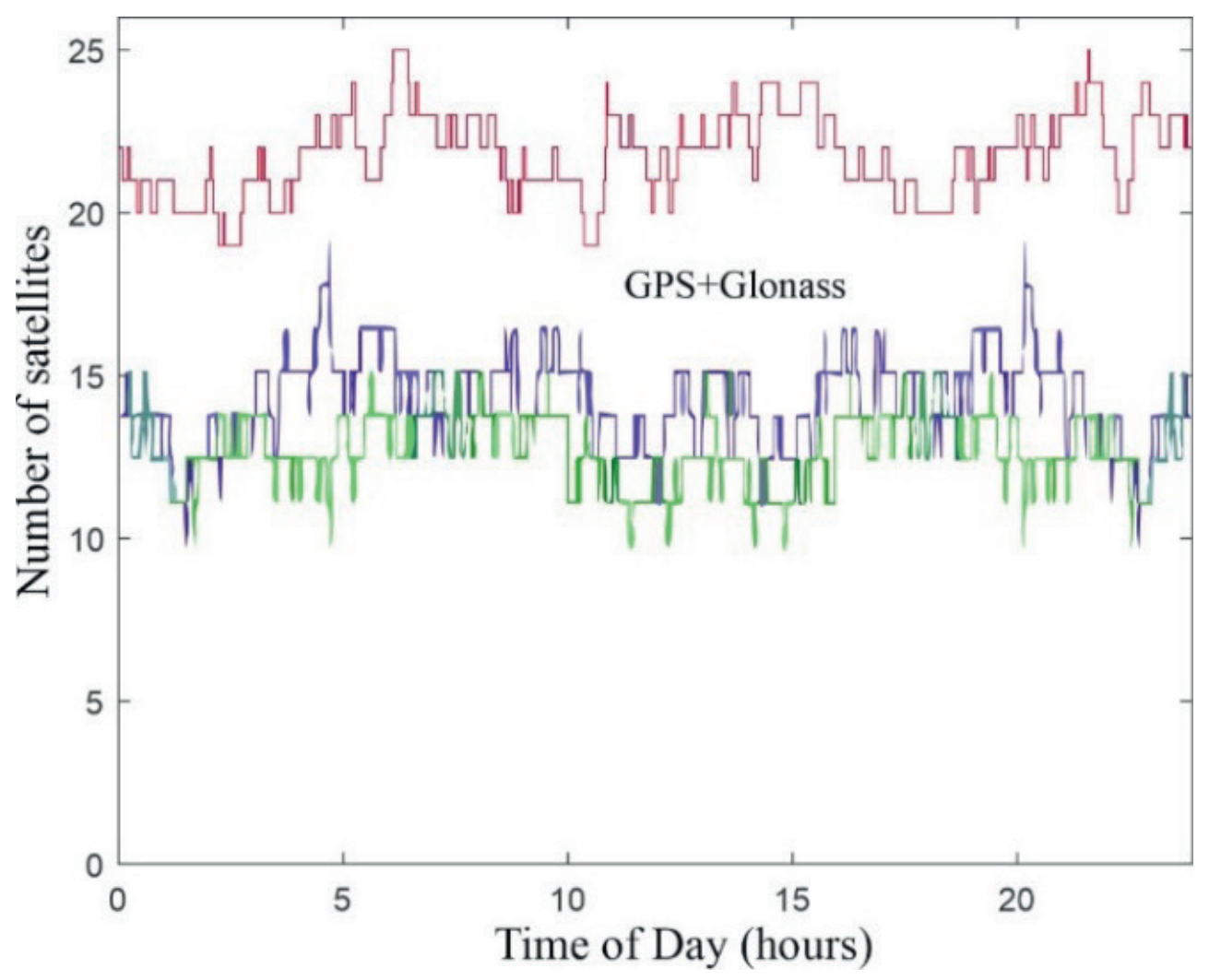

Figure 2 Number of selected GPS (blue line), GLONASS (green line) and GPS + GLONASS (red line) satellites for the static experiment (IGS TITZ and FFMJ station on January 1, 2013)
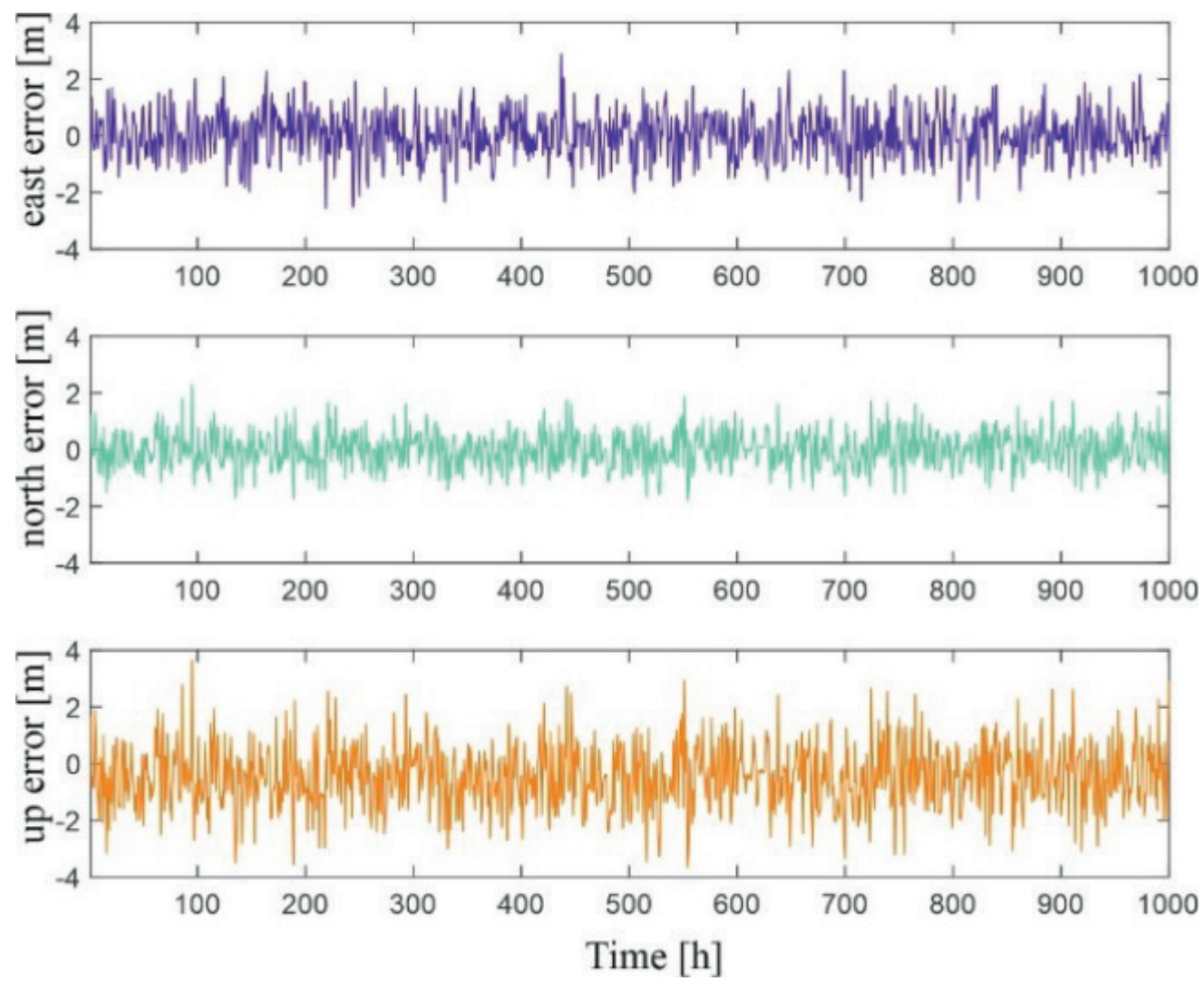

Figure 3 Differences between the IGS result and results of GPS the kinematic system positioning for the TITZ - FFMJ baseline (diagram 1) 

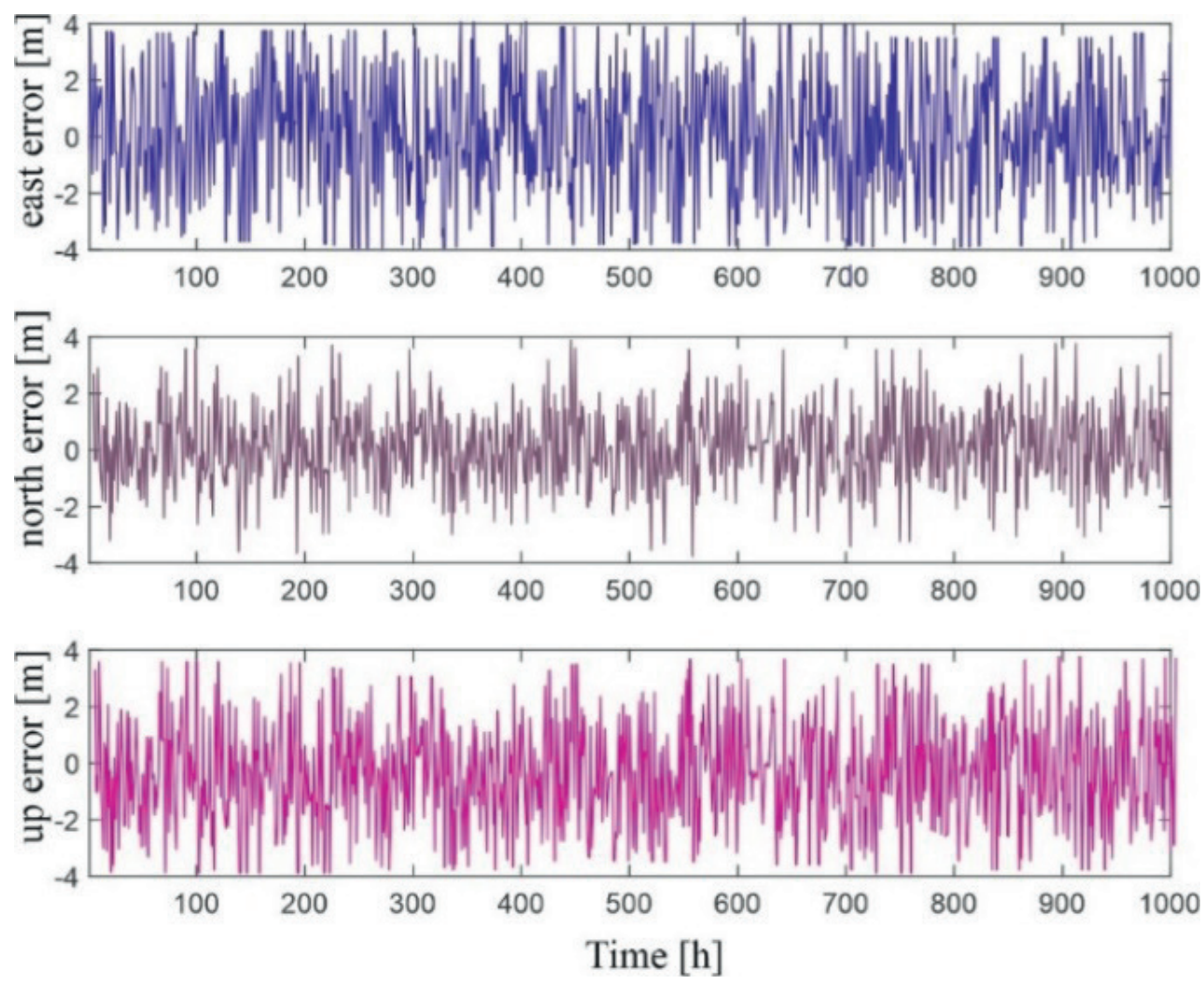

Figure 4 Differences between the IGS result and results of the kinematic system positioning of the GLONASS system for the TITZ - FFMJ baseline (diagram 2)
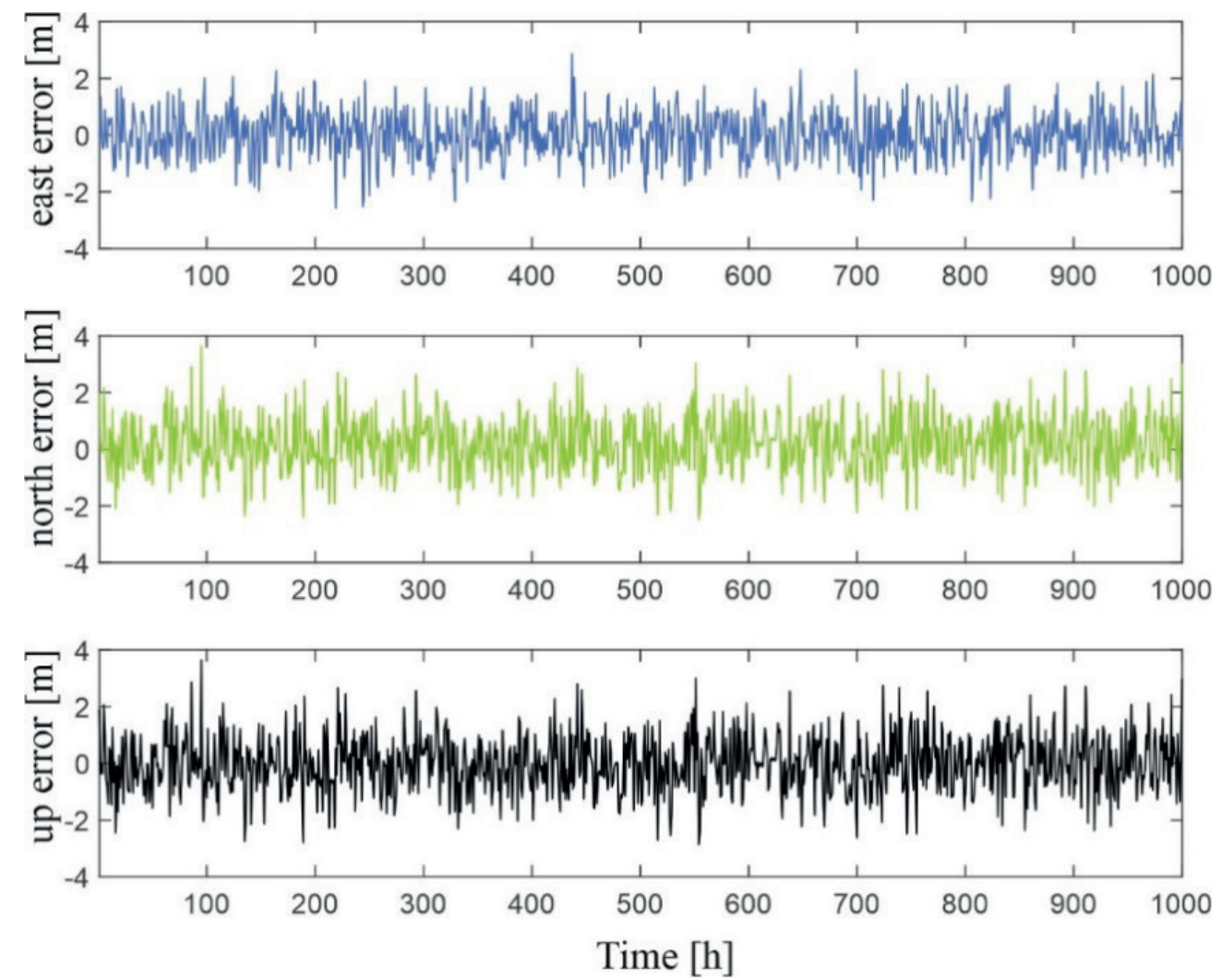

Figure 5 Differences between the IGS result and results of the GPS + GLONASS kinematic positioning (with weights 1:1) for the base line TITZ- FFMJ (diagram 3) 

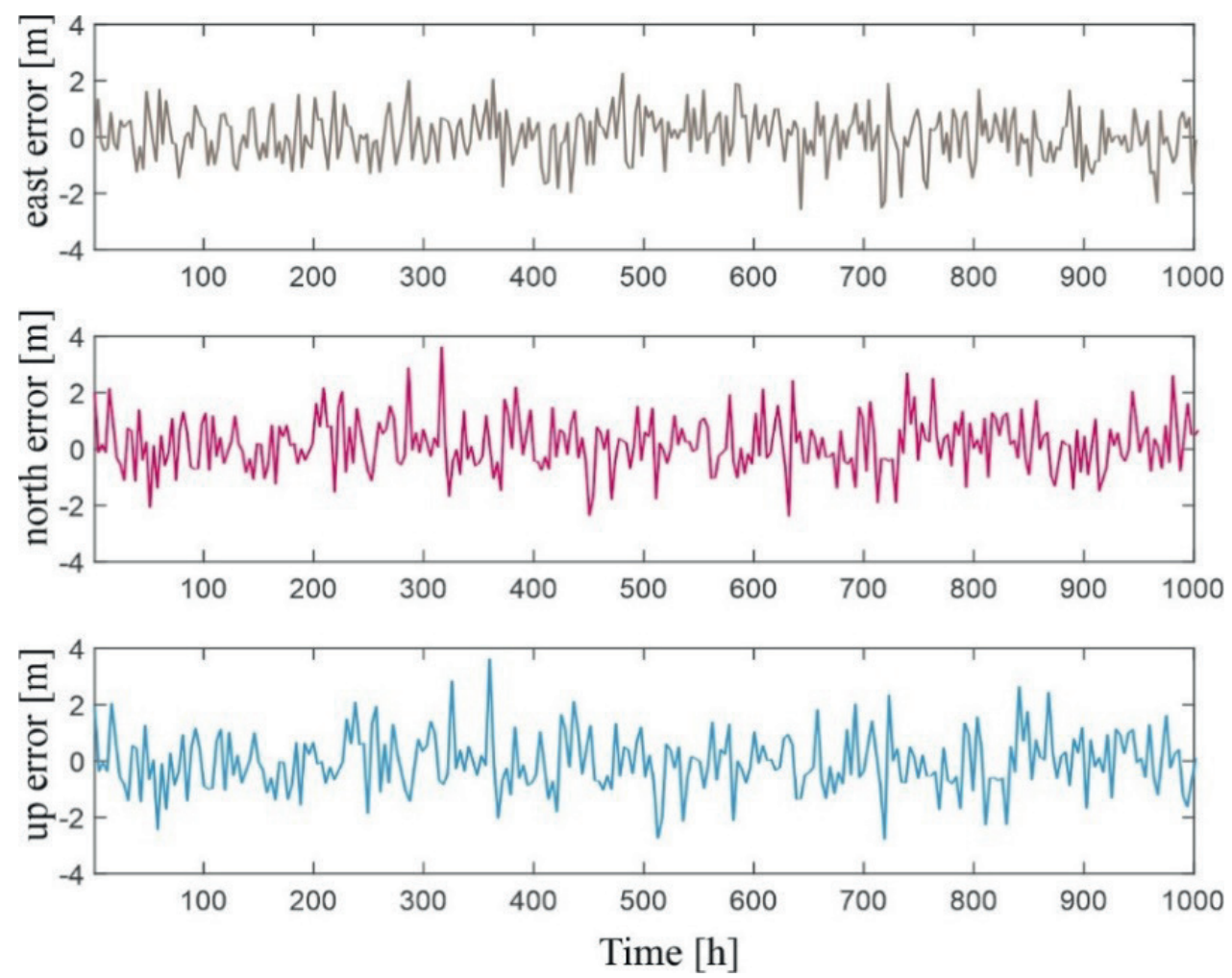

Figure 6 Differences between the IGS result and results of the GPS + GLONASS kinematic positioning (with Helmert weights) for the TITZ - FFMJ baseline (diagram 4)

Table 2 Summary of results

\begin{tabular}{lccc}
\hline & average $(\mathrm{m})$ & rms $(\mathrm{m})$ & standard deviation $(\mathrm{m})$ \\
\hline $\mathrm{X}$ & & experiment 1 & 1.75 \\
$\mathrm{Y}$ & 2.38 & 1.84 & 1.60 \\
$\mathrm{H}$ & 1.29 & 1.62 & 1.55 \\
& 2.77 & 1.57 & 1.88 \\
$\mathrm{X}$ & & experiment 2 & 1.87 \\
$\mathrm{Y}$ & 4.15 & 3.99 & 1.67 \\
$\mathrm{H}$ & 3.32 & 3.19 & \\
& 4.08 & 3.97 & 1.60 \\
$\mathrm{X}$ & & experiment 3 & 1.59 \\
$\mathrm{Y}$ & 2.51 & 2.25 & 1.58 \\
$\mathrm{H}$ & 2.37 & 2.19 & \\
& 2.66 & 2.35 & 1.45 \\
$\mathrm{X}$ & & experiment 4 & 1.74 \\
$\mathrm{Y}$ & 1.78 & 1.57 & 1.68 \\
$\mathrm{H}$ & 3.85 & 3.42 & \\
\hline
\end{tabular}

(more efficient) than their use as individual systems and improves both accuracy and reliability.

It should be noted that the method based on estimation of the VCE Helmert variance component (Variance Component Estimation) can further increase the accuracy of integrated kinematic positioning (Figure 6).
Values of the average differences, maximum, minimum, as well as the RMS error and standard deviation are presented in Table 2.

The conducted research clearly shows that in the case of a localization system in which the systematic error is unknown, accuracy can be determined similarly to the precision, treating the whole as 
a random variable. Differences in results are small, of the order of $3.5 \%$. Although such a solution does not comply with recommendations in the normative regulations and the strict definition of accuracy according to ISO 5725 -1, it may be an alternative form and in the case of location systems it allows to treat all the errors as random ones.

\section{Conclusions}

The presented work has shown that use of the GNSS system integration can improve accuracy and reliable positioning of the GNSS navigation system. In turn, since the Galileo system and the BeiDou satellite navigation system (BDS) have not yet reached full readiness, only the GPS systems and GLONASS were used in this article for research into the combination of multiple systems (Figures 3-6).

Creating the mathematical models and integrated system processing methodologies is valuable because it identifies key issues for connecting two or more GNSS positioning systems. Therefore, these are experiences that can be applied to other GNSS systems that can integrate the GPS system with Galileo, GLONASS, BDS or all four.

The work showed that accuracy of the kinematic positioning of the GNSS system, solely based on the GLONASS system as a single system, is slightly worse than just the GPS system. However, combination of the GPS and GLONASS is better than using them as individual systems and improves accuracy. At the final stage of this article, it was demonstrated that the VCE Helmert method can be used to estimate the weight of many GNSS observation data and can further improve the accuracy of the integrated kinematic positioning of this system.

The GNSS system kinematic positioning method is based on multiple kinematic stations on the same platform with apriori distance constraints and estimation of the common tropospheric delay parameter. In this new method, distances between the multiple GNSS antennas are known and used as apriori distance restrictions to improve accuracy of the state estimates.

In addition, it has been shown that since the characteristics of tropospheric delays in a small area are similar, for such many kinematic stations a common tropospheric delay parameter can be established, which can increase accuracy of the state estimates.

In summary, it can be stated that the kinematic positioning method using the integration of many GNSS systems based on estimation of Helmert's variance components is addressed to adjust the weights in a reasonable way to balance the input of many GNSS systems and improve accuracy of the GNSS navigation kinematic navigation system.

Results of the obtained research allow to formulate the following conclusions:

1. The precise GPS receiver, dedicated to aviation applications, allows for the guidance of objects with an accuracy of about $1 \mathrm{~m}$, even without use of its own Differential Global Positioning System (DGPS) reference station, intended for accurate position determination, thanks to increasing accuracy of the GPS system through the introduced corrections to pseudo-ranges determined by the reference station.

2. The vicinity of tall buildings strongly interferes with the accuracy of the measurement, hence significant errors in guidance should be taken into account in the case of such obstacles.

\section{References}

[1] FENG, Y., WANG, J. Exploring GNSS RTK performance benefits with GPS and virtual galileo measurements. In: Institute of Navigation (ION) National Technical Meeting 2007: proceedings. 2007, p. 218-226.

[2] LANGLEY, R. B. The integrity of GPS. GPS World. 1999, 10(3), p. 60-63. ISSN 1048-5104.

[3] HIGGINS, M. GNSS, CORS and positioning infrastructure: business and the future. In: 6th FIG Regional Conference: proceedings. 2007.

[4] WANG, J. Stochastic modelling for RTK GPS/Glonass positioning. Navigation [online]. 2000, 46(4), p. 297-305. eISSN 2161-4296. Available from: https://doi.org/10.1002/j.2161-4296.1999.tb02416.x

[5] MIRSA, P., ENGE, P. Global positioning systems, signals, measurements and performance. Lincoln: Ganga Jamuna Press, 2004. ISBN 978-0970954428, p. 227-254.

[6] PRATT, M., BURKE, B., MISRA, P. Single-epoch integer ambiguity resolution with GPS-GLONASS L1-L2 data. In: ION GPS-98: proceedings [online]. 1999, p. 1-10. https://rid.trb.org/view/898384

[7] TEUNISSEN, P. J. G. The least-squares ambiguity decorrelation adjustment: a method for fast GPS integer ambiguity estimation. Journal of Geodesy [online]. 1995, 70(1-2), p. 65-82. ISSN 0949-7714, eISSN 1432-1394. Available from: https://doi.org/10.1007/BF00863419.

[8] WANG, J., SATIRAPOD, C., RIZOS, C. Stochastic assessment of GPS carrier phase measurements for precise static relative positioning. Journal of Geodesy [online]. 2002, 76(2), p. 95-104. ISSN 0949-7714. Available from: https://doi.org/10.1007/s00190-001-0225-6.

[9] XU, G. GPS theory, algorithms and applications. 1. ed. Berlin Heidelberg: Springer-Verlag, 2003. ISBN 978-3-540-67812-0. 
[10] GRZEGORZEWSKI, M. Results of a research predicting the position of an aircraft during approach and landing using the bessel function. Journal of Theoretical and Applied Mechanics. 2013, 51(4), p. 915-926. ISSN 1429-2955.

[11] WANG, Z., WU, Y., ZHANG, K., MENG, Y. Triple-frequency method for high-order ionospheric refractive error modelling in GPS modernization. Journal of Global Positioning Systems [online]. 2004, 4(1-2), p. 291-295. ISSN 1446-3156. Available from: https://doi.org/10.5081/jgps.4.1.291

[12] WANNINGER, L., MAY, M. Carrier phase multipath calibration of GPS reference sites. In: 13th International Technical Meeting of the Satellite Division of the Institute of Navigation ION GPS 2000: proceedings. 2000, p. $132-144$.

[13] ENGE, P., VAN DIERENDONCK, A. J. Wide area augmentation system [online]. In: Global Positioning System: theory and applications. Vol II. PARKINSON, B. W., ENGE, P., AXELRAD, P., SPILKER JR., J. J. (eds.). Washington D.C.: American Institute of Aeronautics and Astronautics, 1996. ISBN 978-1-56347-107-0, eISBN 978-1-60086-639-5, p. 117-142. Available from: https://doi.org/10.2514/5.9781600866395.0117.0142

[14] SAUER, K. Integrated high precision kinematic positioning using GPS and EGNOS observations. PhD thesis. London, UK: Department of Civil and Environmental Engineering, Imperial College, 2003.

[15] SETLAK, L., KOWALIK, R. Examination of the unmanned aerial vehicle. ITM Web of Conferences [online]. 2019, 24, 01006. eISSN 2271-2097. Available from: https://doi.org/10.1051/itmconf/20192401006

[16] SCHMITZ, WYBBENA, M., BOETTCHER, G. G. Test of phase centre variations of various GPS antennas and some results. GPS Solutions [online]. 2002, 6(1-2), p. 18-27. ISSN 1080-5370, eISSN 1521-1886. Available from: https://doi.org/10.1007/s10291-002-0008-4

[17] SCHUELER, T., HEIN, G.W., EISSFELLER, B. On the use of numerical weather fields for troposphere delay estimation in wide area augmentation systems. In: GNSS 2000: proceedings. 2000, p. 1077-1091.

[18] TEFERLE, F. N., ORLIAC, E. J., BINGLEY, R. M. An assessment of bernese GPS software precise point positioning using IGS final products for global site velocities. GPS Solution [online]. 2007, 11, p. 205-213. ISSN 1080-5370, eISSN 1521-1886. Available from: https://doi.org/10.1007/s10291-006-0051-7

[19] TSUJII, T., WANG, J., DAI, L., RIZOS, C., HARIGAE, M., INAGAKI, T., FUJIWARA, T. KATO, T. A technique for precise positioning of high altitude platforms system (HAPS) using a GPS ground reference network. In: 14th International Technical Meeting of the Satellite Division of the Institute of Navigation ION-GPS-2001: proceedigs, 2001, p. 1017-1026.

[20] SETLAK, L., KOWALIK, R., SMOLAK, M. Doppler delay in navigation signals received by GNSS receivers. In: WSEAS Transactions on Applied and Theoretical Mechanics, 3rd International Conference on Applied Physics, System Science and Computers APSAC 2018: proceedings. 2018. Lecture Notes in Electrical Engineering. Vol. 574, p. 3-8.

[21] RYAN, S. Y., DATY, A. G., BRAIN, T. D. Investigation and comparison of horizontal protection level and horizontal uncertainty level in FDE algorithms. In: ION GPS 1996: proceedings. 1996, p. 1607-1614.

[22] ZANDBERGEN, DINWIDDY, R. S., HAHN, J., BREEUWER, E., BLONSKI, D. GALILEO orbit selection. In: 17th International Technical Meeting of the Satellite Division of The Institute of Navigation ION GNSS 2004: proceedings. 2004, p. 616-623.

[23] WIESER, A., BRUNNER, F. K. An extended weitht model for GPS phase observations. Earth Planets Space [online]. 2000, 52, p. 777-782. ISSN 1880-5981. Available from: https://doi.org/10.1186/BF03352281

[24] STURZA, M. A. Navigation system integrity monitoring using redundant measurements. Navigation [online]. 1989, 35(4). eISSN 2161-4296. Available from: https://doi.org/10.1002/j.2161-4296.1988.tb00975.x

[25] TEUNISSEN, P. J. G. Least-squares estimation of the integer GPS ambiguities. In: IAG General Meeting: proceedings. Section IV: Theory and Methodology. 1993.

[26] SETLAK, L., KOWALIK, R. Analysis, mathematical model and selected simulation research of the GNSS navigation receiver correlator. MATEC Web of Conferences [online]. 2018, 210, p. 1-11. eISSN 2261-236X. Available from: https://doi.org/10.1051/matecconf/201821005008.

[27] HUGENTOBLER, U., DACH, R., FRIDEZ, P., MEINDL, M. Bernese GPS software version 5.0. Bern: Astronomical Institute University of Bern. 2007.

[28] PARKINSON, B. W., SPILKER Jr., J. J. Global Positioning System: Theory and Applications. Vol. I. Progress in Astronautics and Aeronautics [online]. Washington DC: American Institute of Aeronautics and Astronautics, 1996. ISSN 978-1-56347-106-3, eISSN 978-1-60086-638-8. Available from: https://doi.org/10.2514/4.866388

[29] PULLEN, S. P., PERVAN, B. S., PARKINSON, B. W. A new approach to GPS integrity monitoring using prior probability models and optimal threshold search. In: PLANS '94: proceedings. 1994.

[30] RAQUET, J. F. Development of a method for kinematic GPS carrier-phase ambiguity resolution using multiple reference receivers. PhD. Thesis. Calgary: University of Calgary, Department of Geomatics Engineering, 1998.

[31] REMONDI, B. W. NGS second generation ASCII and binary orbit formats and associated interpolation studies. In: 20th general assembly of the IUGG: proceedings. 1991. 
[32] RICHERT, T., EL-SHEIMY, N. Optimal linear combinations of triple frequency carrier phase data from future global navigation satellite systems. GPS Solutions [online]. 2007, 11(1), p. 11-19. ISSN 1080-5370, eISSN 1521-1886. Available from: https://doi.org/10.1007/s10291-006-0024-x

[33] ROTHACHER, M., SPRINGER, T. A., SCHAER, S., BEUTLER, G. Processing strategies for regional GPS networks. In: IAG General Assembly: proceedings. Springer, 1997.

[34] ENGE, P. K. The Global Positioning System: signals, measurements,and performance, International Journal of Wireless Information Networks [online]. 1994, 1(2), p. 83-105. ISSN 1068-9605, eISSN 1572-8129. Available from: https://doi.org/10.1007/BF02106512

[35] ZHANG, W. Triple frequency cascading ambiguity resolution for modernized GPS and GALILEO. UCGE reports, No. 20228. Calgary: University of Calgary, Department of Geomatics Engineering, 2005.

[36] SETLAK, L., KOWALIK, R. Examination of multi-pulse rectifiers of PES systems used on airplanes compliant with the concept of electrified aircraft. Applied Sciences [online]. 2019, 9(8), 1520. Available from: https://doi.org/10.3390/app9081520

[37] ZHANG, X. H., ANDERSON, O. B. Surface ice flow velocity and tide retrieval of the amery ice shelf using precise point positioning. Journal of Geodesy [online]. 2006, 80(4), p. 171-176. ISSN 0949-7714, eISSN 1432-1394. Available from: https://doi.org/10.1007/s00190-006-0062-8

[38] YOUSIF, H., EL-RABBANY, A. Assessment of several interpolation methods for precise GPS orbit. The Journal of Navigation [online]. 2007, 60, p. 443-455. ISSN 0373-4633, eISSN 1469-7785. Available from: https://doi. org/10.1017/S0373463307004250.

[39] SETLAK, L., KOWALIK, R. Analysis, mathematical model and simulation tests of the unmanned aerial vehicle control system. ITM Web of Conferences [online]. 2019, 24, 01005. eISSN 2271-2097. Available from: https://doi. org/10.1051/itmconf/20192401005

[40] WYBBEnA, G., SCHMiTZ, M., MENGE, F., BODER, V., SEEBER, G. Automated absolute field calibration of GPS antennas in real time. In: International Technical Meeting of the Satellite Division of the Institute of Navigation ION-GPS-2000: proceedings. 2000, p. 2512-2522.

[41] WERNER, W., WINKEL, J. TCAR and MCAR options with GALILEO and GPS. In: ION GPS/GNSS 2003: proceedings. 2002.

[42] TEUNISSEN, P. J. G., DE JONGE, P. J., TIBERIOUS, C. C. J. M Performance of the LAMBDA method for fast GPS ambiguity resolution. Navigation [online]. 1997, 44(3), p. 373-383. eISSN 2161-4296. Available from: https://doi.org/10.1002/j.2161-4296.1997.tb02355.x 